\title{
Metagenomic and metaproteomic insights into bacterial communities in leaf-cutter ant fungus gardens
}

\author{
Frank O Aylward ${ }^{1,2}$, Kristin E Burnum ${ }^{3}$, Jarrod J Scott ${ }^{1,2,4}$, Garret Suen ${ }^{1,2}$, \\ Susannah G Tringe ${ }^{5}$, Sandra M Adams ${ }^{1,2}$, Kerrie W Barry ${ }^{5}$, Carrie D Nicora ${ }^{3}$, \\ Paul D Piehowski ${ }^{3}$, Samuel O Purvine ${ }^{3}$, Gabriel J Starrett ${ }^{1,2}$, Lynne A Goodwin ${ }^{5}$, \\ Richard D Smith ${ }^{3}$, Mary S Lipton ${ }^{3}$ and Cameron R Currie ${ }^{1,2,4}$ \\ ${ }^{1}$ Department of Bacteriology, University of Wisconsin-Madison, Madison, WI, USA; ${ }^{2}$ Department of Energy \\ Great Lakes Bioenergy Research Center, University of Wisconsin-Madison, Madison, WI, USA; ${ }^{3}$ Biological \\ Sciences Division, Pacific Northwest National Laboratory, Richland, WA, USA; ${ }^{4}$ Smithsonian Tropical \\ Research Institute, Balboa, Ancon, Panama and ${ }^{5}$ Department of Energy Joint Genome Institute, Walnut Creek, \\ $C A, U S A$
}

\begin{abstract}
Herbivores gain access to nutrients stored in plant biomass largely by harnessing the metabolic activities of microbes. Leaf-cutter ants of the genus Atta are a hallmark example; these dominant neotropical herbivores cultivate symbiotic fungus gardens on large quantities of fresh plant forage. As the external digestive system of the ants, fungus gardens facilitate the production and sustenance of millions of workers. Using metagenomic and metaproteomic techniques, we characterize the bacterial diversity and physiological potential of fungus gardens from two species of Atta. Our analysis of over $1.2 \mathrm{Gbp}$ of community metagenomic sequence and three $16 \mathrm{~S}$ pyrotag libraries reveals that in addition to harboring the dominant fungal crop, these ecosystems contain abundant populations of Enterobacteriaceae, including the genera Enterobacter, Pantoea, Klebsiella, Citrobacter and Escherichia. We show that these bacterial communities possess genes associated with lignocellulose degradation and diverse biosynthetic pathways, suggesting that they play a role in nutrient cycling by converting the nitrogen-poor forage of the ants into B-vitamins, amino acids and other cellular components. Our metaproteomic analysis confirms that bacterial glycosyl hydrolases and proteins with putative biosynthetic functions are produced in both fieldcollected and laboratory-reared colonies. These results are consistent with the hypothesis that fungus gardens are specialized fungus-bacteria communities that convert plant material into energy for their ant hosts. Together with recent investigations into the microbial symbionts of vertebrates, our work underscores the importance of microbial communities in the ecology and evolution of herbivorous metazoans.
\end{abstract}

The ISME Journal (2012) 6, 1688-1701; doi:10.1038/ismej.2012.10; published online 1 March 2012

Subject Category: integrated genomics and post-genomics approaches in microbial ecology

Keywords: leaf-cutter ants; symbiosis; Leucoagaricus gongylophorus; microbial consortia; Atta

\section{Introduction}

Ants are critical components of terrestrial ecosystems around the world (Hölldobler and Wilson, 1990). Among ants, leaf-cutters in the genus Atta (Figure 1a) are particularly dominant, with mature colonies achieving immense sizes and housing millions of workers (Hölldobler and Wilson, 2008, 2010). Ranging from the southern United States to Argentina, species of leaf-cutter ants can construct

Correspondence: CR Currie, Department of Bacteriology, University of Wisconsin-Madison, 6155 Microbial Sciences Building, 1550 Linden Drive, Madison, WI 53706, USA.

E-mail: currie@bact.wisc.edu

Received 9 August 2011; revised 12 December 2011; accepted 21 January 2012; published online 1 March 2012 elaborate subterranean nests containing hundreds of chambers and displacing up to $40000 \mathrm{~kg}$ of soil (Hölldobler and Wilson, 2010). The ant societies housed within these nests are equally impressive, with an intricate division of labor observed between different castes of workers (Hölldobler and Wilson, 2010). Associated with this division of labor is substantial worker-size polymorphism: the dry weight of individual workers in the same colony can differ by 200-fold (Hölldobler and Wilson, 2010). The success of leaf-cutter ants is largely attributed to their obligate mutualism with a basidiomycetous fungus (Leucoagaricus gongylophorus) that they culture for food in specialized gardens (Figure 1b) (Weber, 1966; Hölldobler and Wilson, 2008, 2010). Fresh plant forage collected by the ants serves to nourish the fungus, which in turn 

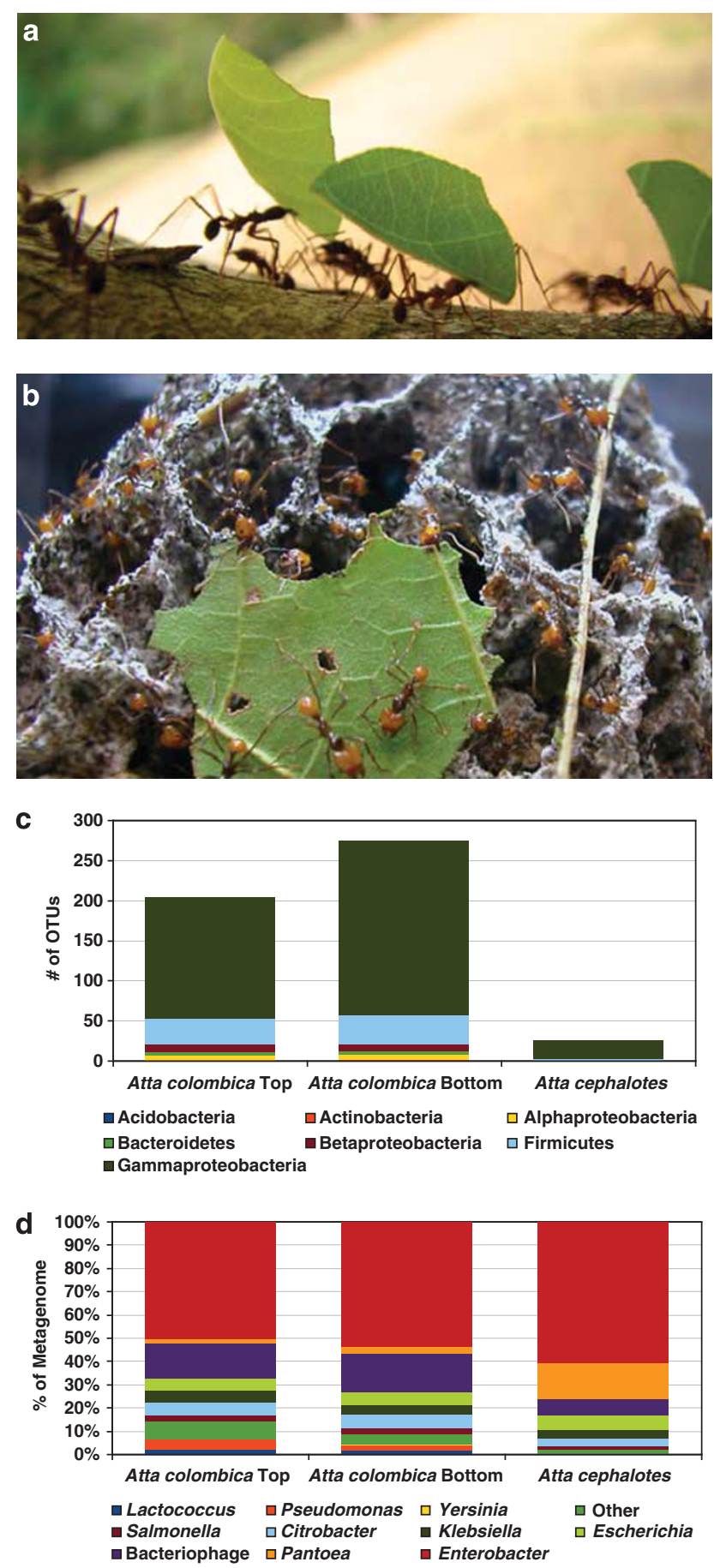

Figure 1 Leaf cutter ants forage on plant material (a) that they use as manure for specialized fungus gardens (b). Pyrosequencing of bacterial $16 S$ genes from fungus gardens of the leaf-cutter ants A. colombica and A. cephalotes recovered 8000-12 000 sequences representing 25-274 OTUs (OTUs, 97\% identity cutoff) (c). Microbial community composition was then investigated by directly pyrosequencing $382-441 \mathrm{Mbp}$ of DNA from the same leaf-cutter ant fungus gardens and using the Genome Abundance and Average Size tool to estimate the relative abundance of different microbial groups (d) (photo credits: a, Jarrod J Scott; b, Austin D Lynch).

produces nutrient-rich hyphal swellings (gongylidia) that feed the colony (Weber, 1966). The symbiosis between leaf-cutter ants and their cultivar is thought to have originated 8-12 million years ago, and numerous adaptations in both the ants and the fungus have occurred over this long history of agriculture (Weber, 1966; Chapela et al., 1994; Schultz and Brady, 2008).

The fresh-foliar biomass leaf-cutter ants integrate into their fungus gardens is composed largely of recalcitrant lignocellulosic polymers. The ants presumably gain indirect access to the carbon stored in plant cell walls through the metabolic activities of their fungus gardens, which act as an ancillary digestive system (Pinto-Tomas et al., 2009). Despite being a critical aspect of leaf-cutter ant biology, the process through which fungus gardens degrade plant forage has only recently been intensely investigated (De Fine Licht et al., 2010; Schiott et al., 2010; Suen et al., 2010; Semenova et al., 2011). Originally it was thought that the fungal cultivar primarily degraded cellulose, and that this was the main polymer converted into nutrients for the ants (Martin and Weber, 1969). However, the cellulolytic capacity of this fungus has come into question, as it has been shown that pure cultures cannot grow on cellulose as a sole carbon source (Abril and Bucher, 2002). This has led to the suggestion that cellulose is not deconstructed in leaf-cutter ant fungus gardens, but rather that the fungal cultivar uses a variety of hemicellulases to deconstruct primarily starch, xylan and other plant polymers (Gomes De Siqueira et al., 1998; Silva et al., 2006a, b; Schiott et al., 2008).

Another model posits that plant cell wall degradation in fungus gardens is partially mediated by lignocellulolytic bacteria. There is some support for this model. Importantly, recent work has found evidence for substantial cellulose deconstruction in the fungus gardens of Atta colombica and the presence of lignocellulolytic bacteria in these ecosystems (Suen et al., 2010). Another study, employing the culture-independent analysis of membrane-lipid markers, has supported the hypothesis that a distinct community of predominantly Gram-negative bacteria resides in fungus gardens (Scott et al., 2010), and the presence of symbiotic nitrogen-fixing bacteria in the genera Pantoea and Klebsiella has also been shown (Pinto-Tomas et al., 2009). Together with culture-dependent investigations recovering microbial groups with a broad array of metabolic activities (Bacci et al., 1995; Santos et al., 2004), these experiments have led to the suggestion that fungus gardens represent specialized fungusbacteria consortia selected for by the ants, and that the bacteria have essential roles, including plant biomass degradation, nutrient biosynthesis, and competitive or antibiotic-mediated exclusion of pathogens (Mueller et al., 2005; Haeder et al., 2009; Pinto-Tomas et al., 2009; Suen et al., 2010).

Using a combination of metagenomics and metaproteomics, we provide insights into the microbial activities in leaf-cutter ant fungus gardens. Cultureindependent investigations have previously been 
performed on leaf-cutter ant fungus gardens (Scott et al., 2010; Suen et al., 2010), but to date only a small quantity of bacterial sequences $(\sim 6 \mathrm{Mb})$ from the fungus gardens of a single ant species have been characterized. Here, by expanding on previous work, we sought to document the non-eukaryotic component of fungus gardens, describe the similarity of communities from different ant species and examine potential microbial activities in situ. To this end, we generated three $16 \mathrm{~S}$ pyrotag libraries of over 8000 sequences each and over $1.2 \mathrm{Gbp}$ of raw 454 Titanium community metagenomic data from the bacterial component of $A$. cephalotes and A. colombica fungus gardens. To account for potential differences in microbial communities due to the extent of plant biomass degradation, we individually examined the top and bottom strata of A. colombica fungus gardens, which correspond to where the ants integrate fresh forage and remove partially degraded plant substrate, respectively. We then conducted metaproteomic analyses on whole fungus gardens to identify proteins produced in these ecosystems and examine the physiology of resident bacteria in more detail. We found that similar bacterial communities inhabit all fungusgarden samples analyzed, and that the metabolic potential of resident bacteria includes nutrient biosynthesis, hemicellulose and oligosaccharide degradation, and other functions that potentially enhance plant biomass processing in these ecosystems. Below we discuss a novel framework for understanding the complex interplay between leafcutter ants and the symbiotic communities residing in their fungus gardens.

\section{Materials and methods}

Sample processing for community metagenomes and $16 S$ pyrotag libraries

Fungus gardens from healthy $A$. cephalotes and $A$. colombica colonies were collected from nests near Gamboa, Panama, in April 2009. Whole A. cephalotes gardens were combined for subsequent analyses, whereas fungus gardens of $A$. colombica were laterally bisected to separate the top and bottom strata. Immediately after collection, the bacterial fraction of the samples was isolated and DNA was extracted as previously described (Suen et al., 2010). Briefly, plant, ant and fungal material were removed from all samples through a series of washing or centrifugation steps using $1 \times \mathrm{PBS}(137 \mathrm{mM} \mathrm{NaCl}$,

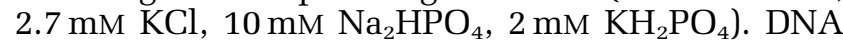
was subsequently extracted from the remaining bacterial fraction using a Qiagen DNeasy Plant Maxi Kit (Qiagen Sciences, Germantown, MD, USA). One community metagenome and one $16 \mathrm{~S}$ library were generated from each of the three samples using 454 Titanium-pyrosequencing technology (Margulies et al., 2005). Draft genomes of three bacteria isolated from Atta fungus gardens were also generated to supplement the reference databases used for the phylogenetic binning of metagenomic data. Technical details for the sequencing, assembly, and annotation of all data can be found in the Supplementary Information.

\section{Metaproteomics}

Metaproteomic analysis was conducted on fungusgarden material collected in Gamboa, Panama, from a nest of $A$. colombica distinct from that used for metagenomic analyses. Moreover, we also conducted metaproteomic analyses on a lab-reared colony of $A$. sexdens for comparison. Detailed methods can be found in Supplementary Information. Briefly, proteins were extracted from whole fungus-garden material, and the resulting protein solution was digested into peptides and subsequently analyzed by liquid chromatography tandem mass spectrometry (LC-MS/MS). The resulting peptide tandem mass spectra were compared with predicted protein datasets of the three community metagenomes individually. Peptide matches were filtered using Sequest (Eng et al., 1994) scores, MSGF spectral probabilities (Kim et al., 2008), and false discovery rates. We restricted our functional analyses to peptides mapped to proteins phylogenetically binned as bacterial, and the IMG-ER and KEGG annotations of these proteins were inspected to identify those potentially involved in biomass degradation or nutrient cycling (Table 5). Peptides mapping to these select proteins were inspected manually (Figure 5, Supplementary Dataset 6).

\section{Results}

Community metagenomes and 165 pyrotag libraries Pyrosequencing of the V6-V8 variable region of the bacterial 16S rRNA gene for the same three samples yielded between 8000-12000 reads (termed 'pyrotags') each (Table 2). Previous attempts to recover Archaeal 16S sequences from fungus gardens were unsuccessful (Suen et al., 2010), and amplification of these genes was not attempted here. Pyrosequencing of community DNA from three samples, representing both the individual top and bottom strata of $A$. colombica fungus gardens as well as the combined strata of $A$. cephalotes gardens, each yielded 382-441 Mb of raw sequence data (Table 1). Reads from each library were assembled into community metagenomes comprising $40-100 \mathrm{Mbp}$ of sequence data.

\section{Microbial diversity in fungus gardens}

Clustering of sequences in the 16S pyrotag libraries from the A. colombica top, A. colombica bottom and A. cephalotes fungus-garden samples recovered 204, 274 and 25 operational taxonomic units (OTUs, $97 \%$ identity cutoff), respectively. The majority of the OTUs were most similar to sequences of 
Table 1 Sequencing statistics of the community metagenomes

\begin{tabular}{|c|c|c|c|}
\hline Ant species & A. colombica top & A. colombica bottom & A. cephalotes \\
\hline Number of trimmed reads & 998047 & 862246 & 1068791 \\
\hline Amount of raw sequence (Mbp) & 441.2 & 382.1 & 431.0 \\
\hline Number of contigs & 28034 & 21203 & 17914 \\
\hline Largest contig (kbp) & 359.8 & 361.9 & 168.3 \\
\hline N50 contig size (kbp) & 1.8 & 1.8 & 4.7 \\
\hline Number of singleton reads & 188523 & 161267 & 55949 \\
\hline Protein coding genes & 240966 & 199019 & 73881 \\
\hline Size of assembled data (Mbp) & 100.9 & 83.2 & 40.6 \\
\hline
\end{tabular}

Table 2 Family-level classification of partial-length 16S sequences recovered from Atta colombica and Atta cephalotes fungus gardens

\begin{tabular}{|c|c|c|c|c|c|c|c|c|c|}
\hline \multirow[t]{2}{*}{ Family } & \multicolumn{3}{|c|}{ A. colombica top } & \multicolumn{3}{|c|}{ A. colombica bottom } & \multicolumn{3}{|c|}{ A. cephalotes } \\
\hline & OTUs & Clones & OTUs (\%) & OTUs & Clones & OTUs (\%) & OTUs & Clones & OTUs $(\%)$ \\
\hline Acetobacteraceae & 1 & 3 & 0.49 & 2 & 36 & 0.73 & 1 & 2 & 4.00 \\
\hline Aeromonadaceae & 5 & 13 & 2.45 & 0 & 0 & 0.00 & 0 & 0 & 0.00 \\
\hline Alcaligenaceae & 1 & 7 & 0.49 & 2 & 3 & 0.73 & 0 & 0 & 0.00 \\
\hline Aurantimonadaceae & 0 & 0 & 0.00 & 0 & 0 & 0.00 & 0 & 0 & 0.00 \\
\hline Bacillaceae & 5 & 45 & 2.45 & 8 & 156 & 2.92 & 1 & 5 & 4.00 \\
\hline Carnobacteriaceae & 3 & 197 & 1.47 & 6 & 273 & 2.19 & 1 & 2 & 4.00 \\
\hline Clostridiaceae & 3 & 3 & 1.47 & 1 & 1 & 0.36 & 0 & 0 & 0.00 \\
\hline Comamonadaceae & 7 & 474 & 3.43 & 5 & 296 & 1.82 & 0 & 0 & 0.00 \\
\hline Enterobacteriaceae & 129 & 6502 & 63.24 & 202 & 10706 & 73.72 & 19 & 10496 & 76.00 \\
\hline Enterococcaceae & 5 & 66 & 2.45 & 0 & 0 & 0.00 & 0 & 0 & 0.00 \\
\hline Flavobacteriaceae & 3 & 33 & 1.47 & 2 & 21 & 0.73 & 0 & 0 & 0.00 \\
\hline Moraxellaceae & 3 & 167 & 1.47 & 2 & 64 & 0.73 & 1 & 2 & 4.00 \\
\hline Paenibacillaceae & 2 & 15 & 0.98 & 3 & 3 & 1.09 & 0 & 0 & 0.00 \\
\hline Pseudomonadaceae & 10 & 335 & 4.90 & 9 & 345 & 3.28 & 1 & 3 & 4.00 \\
\hline Ruminococcaceae & 3 & 7 & 1.47 & 4 & 14 & 1.46 & 0 & 0 & 0.00 \\
\hline Sphingomonadaceae & 3 & 11 & 1.47 & 2 & 4 & 0.73 & 0 & 0 & 0.00 \\
\hline Staphylococcaceae & 4 & 13 & 1.96 & 4 & 6 & 1.46 & 0 & 0 & 0.00 \\
\hline Veillonellaceae & 0 & 0 & 0.00 & 4 & 96 & 1.46 & 0 & 0 & 0.00 \\
\hline Xanthomonadaceae & 4 & 134 & 1.96 & 2 & 60 & 0.73 & 1 & 1 & 4.00 \\
\hline Other & 13 & 163 & 6.00 & 16 & 86 & 6.00 & 0 & 0 & 0.00 \\
\hline Total & 204 & 8188 & 100 & 274 & 12170 & 100 & 25 & 10511 & 100 \\
\hline
\end{tabular}

Gammaproteobacteria and Firmicutes (22-217 OTUs, $72-89 \%$ of OTUs, and $2-35$ OTUs, $5-12 \%$ of OTUs, respectively), and only OTUs corresponding to those phyla were represented in all three samples (Figure 1c). Phyla represented in lower abundance and more sporadically included the Betaproteobacteria ( $\leqslant 10$ OTUs, $\leqslant 4.9 \%$ of OTUs), Alphaproteobacteria ( $\leqslant 7$ OTUs, $\leqslant 3.4 \%$ of OTUs), Bacteriodetes $(\leqslant 4$ OTUs, $\leqslant 2 \%$ of OTUs), Acidobacteria ( $\leqslant 1$ OTU, $\leqslant 1 \%$ of OTUs) and Actinobacteria ( $\leqslant 1$ OTU, $\leqslant 4 \%$ of OTUs) (Figure $1 \mathrm{c}$ ). Most pyrotags corresponded to the Gammaproteobacterial family Enterobacteriaceae (79-99\% of individual pyrotags, Table 2). Although taxonomic profiles were similar in all three pyrotag libraries, the bacterial diversity of each of the $A$. colombica samples was greater than that recovered from the A. cephalotes fungus garden sample.

Community metagenomic analyses recovered primarily bacterial sequences $(71-80 \%$ of total assembled bp) (Table 3). Consistent with the $16 \mathrm{~S}$ pyrotag libraries, the majority of sequences in all three data sets matched most closely to Gammaproteobacteria (69-72\%), especially Enterobacteriaceae $(53-70 \%)$. To refine taxonomic resolution and infer the relative abundance of microbial groups, raw reads were phylogenetically classified using the Genome relative Abundance and Average Size (GAAS) tool (Angly et al., 2009). Estimates based on GAAS analyses indicate that the Gammaproteobacteria were particularly abundant, with the genus Enterobacter comprising over $50 \%$ of the bacterial population in all the three metagenomes (Figure 1d). The community metagenomes also contained representative sequences from the genera Klebsiella (3.8-4.9\%), Pantoea (1.8-15.6\%), Escherichia (5.3-6.3\%), Citrobacter (3-5.8\%), Pseudomonas $(0.04-4.2 \%)$ and Lactococcus $(0.01-2.2 \%)$. BLAST-based classification of the assembly indicated that $\sim 1 \%$ of the sequences corresponded to bacteriophage in each of the community metagenomes (Table 3), whereas the GAAS tool estimated 
Table 3 Phylogenetic classification of all assembled contigs and singletons in the leaf-cutter ant fungus garden metagenomes

\begin{tabular}{|c|c|c|c|}
\hline \multirow[t]{2}{*}{ Classification } & \multicolumn{3}{|c|}{$k b$ of sequence (\% of assembly) } \\
\hline & A. cephalotes & A. colombica top & A. colombica bottom \\
\hline Bacteria & $29058.8(71.5 \%)$ & $78823.2(78.1 \%)$ & $66803.1(80.3 \%)$ \\
\hline Proteobacteria & $28985.3(71.4 \%)$ & $75187.6(74.5 \%)$ & $63493.9(76.3 \%)$ \\
\hline Gammaproteobacteria & $28697.4(70.6 \%)$ & $69374(68.8 \%)$ & $59665.8(71.7 \%)$ \\
\hline Enterobacteriaceae & $28225.4(69.5 \%)$ & $53004.3(52.5 \%)$ & $49280.1(59.3 \%)$ \\
\hline Pseudomonadaceae & $222.8(0.55 \%)$ & $8973.2(8.9 \%)$ & $6741.7(8.1 \%)$ \\
\hline Betaproteobacteria & $185.6(0.45 \%)$ & $4940.9(4.9 \%)$ & $3171(3.8 \%)$ \\
\hline Alphaproteobacteria & $99.4(0.24 \%)$ & $822.5(0.82 \%)$ & $612.1(0.74 \%)$ \\
\hline Firmicutes & $29.1(0.07 \%)$ & $3167.7(3.1 \%)$ & $3043.64(3.6 \%)$ \\
\hline Actinobacteria & $19.4(0.05 \%)$ & $106.6(0.11 \%)$ & $82.5(0.01 \%)$ \\
\hline Bacteroidetes & $17.9(0.04 \%)$ & $281.8(0.28 \%)$ & $124.1(0.15 \%)$ \\
\hline Eukaryota & $661.3(1.6 \%)$ & $145.1(0.14 \%)$ & $133.5(0.16 \%)$ \\
\hline Fungi & $495.6(1.2 \%)$ & $14.2(0.01 \%)$ & $25.1(0.03 \%)$ \\
\hline Metazoa & $19.8(0.05 \%)$ & $81.5(0.08 \%)$ & $66.4(0.08 \%)$ \\
\hline Viridiplantae & $143.4(0.35 \%)$ & $35.6(0.04 \%)$ & $35.2(0.04 \%)$ \\
\hline Viruses & $102.2(0.25 \%)$ & $727.6(0.72 \%)$ & $947.6(1.1 \%)$ \\
\hline dsDNA viruses & $85.9(0.21 \%)$ & $713.9(0.71 \%)$ & $579.6(0.7 \%)$ \\
\hline ssDNA viruses & $15.3(0.04 \%)$ & $11.6(0.01 \%)$ & $367.25(0.44 \%)$ \\
\hline Other & $60.1(<0.01 \%)$ & $132.8(<0.01 \%)$ & $105.8(<0.01 \%)$ \\
\hline Unclassified & $10741(26.4 \%)$ & $21076.2(20.9 \%)$ & $15177.1(18.2 \%)$ \\
\hline
\end{tabular}

BLASTN was used to compare all sequences to NCBI's non-redundant nucleotide database.

that $15.1 \%, 16.8 \%$ and $6.8 \%$ of the $A$. colombica top, A. colombica bottom and A. cephalotes metagenomes could be comprised of bacteriophage, respectively.

Consistent with the GAAS- and BLAST-based analyses, the largest phylogenetic bins created by phymmBL were assigned to the genera Enterobacter, Pantoea, Klebsiella, Escherichia, Citrobacter and Pseudomonas. The Enterobacter bins were by far the largest, containing $15.3-29.5 \mathrm{Mb}$ of sequence. The majority of these sequences were most similar to the draft genome of Enterobacter FGI 35, a strain isolated in this study from an A. colombica fungus garden. The Pantoea bins were the next largest, containing between $5-7.2 \mathrm{Mb}$ of sequence each.

\section{Metabolic potential of bacterial lineages}

To compare the coding potential of different bacterial groups in fungus gardens, we analyzed genuslevel phylogenetic bins of sequences constructed from the community metagenomes. Comparison of the coding potential in the bins with the KEGG database (Kanehisa et al., 2008) recovered wellrepresented sugar metabolism pathways in most of the Enterobacteriaceae bins (Figure 2). Moreover, pathways involved in B-vitamin and amino-acid metabolism were found to be highly represented in both the Pseudomonas and Enterobacteriaceae bins. The Lactococcus bins showed relatively low representation in most of these pathways. Clustering of phylogenetic bins from each of the metagenomes by their KEGG pathway representation indicated that bacterial members corresponding to the same genus, with the exception of Citrobacter, had similar metabolic profiles.

To examine how leaf-cutter ant fungus garden microbial communities differed from other environments, we predicted Clusters of Orthologous Groups (COGs (Tatusov et al., 2001)) from all contigs and reads from the three fungus-garden metagenomes and compared these with COG profiles from all other metagenomes available on the Integrated Microbial Genomes/Microbiomes (IMG/M) database (Markowitz et al., 2008) (Figure 3). COG profiles for the three fungus-garden metagenomes were found to be highly similar. Compared with all other metagenomes on IMG, many COG categories were overrepresented in fungus gardens (Fisher's exact test, $P<0.01$ ), including amino-acid transport and metabolism, carbohydrate transport and metabolism, and inorganic ion transport and metabolism (Figure 3). Specific COGs involved in carbohydrate transport and metabolism were analyzed in more detail to investigate possible bacterial roles in polysaccharide degradation, and sugar transporters and phosphotransferase system components in particular were found to be significantly overrepresented in the fungus-garden metagenomes (Fisher's exact test, $P<0.01$ ) (Supplementary Dataset S2).

To further investigate potential bacterial roles in plant-polymer deconstruction, we compared all predicted proteins in the three community metagenomes with the carbohydrate active enzymes (CAZy) database (Cantarel et al., 2009) and identified numerous enzymes potentially involved in this 

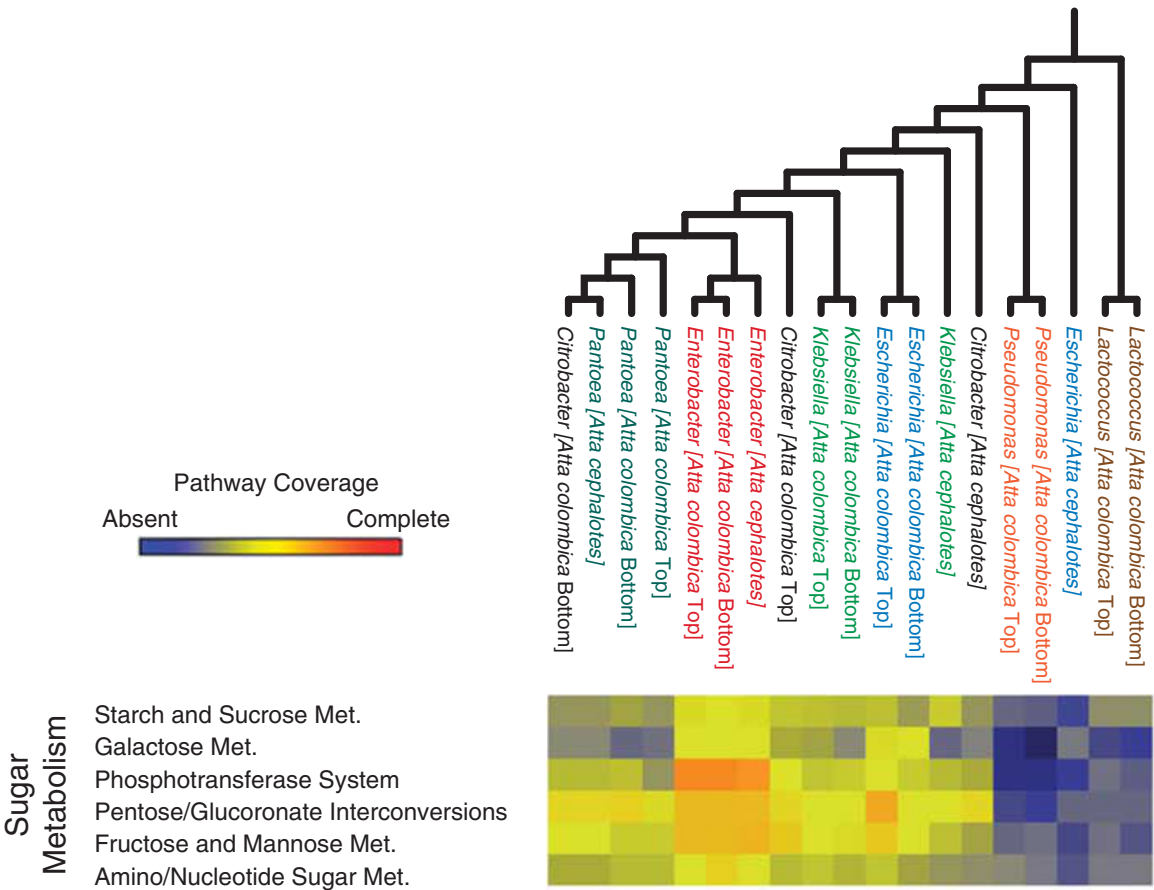

Beta-Alanine Met.

Histidine Met.

Arginine/Proline Met.

은 트 Phenylalanine/Tyrosine/Tryptophan Met

$\varangle$ Selenoamino Acid Met.

으 음 Cysteine/Methionine Met.

है D-Glutamine/D-Glutamate Met.

Glycine/Serine/Threonine Met.

Alanine/Aspartate/Glutamate Met.

Valine/Leucine/Isoleucine Met.

Lysine Biosyn.
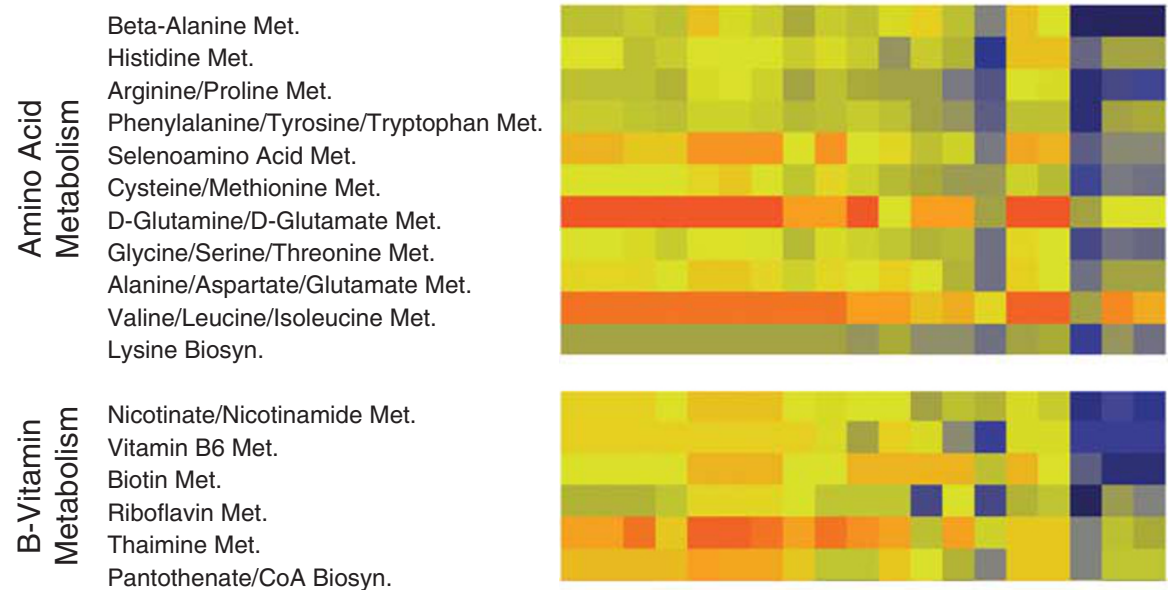

Flagellar Assembly Bacterial Chemotaxis

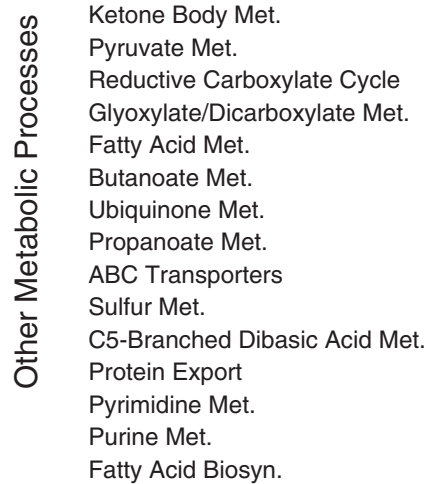

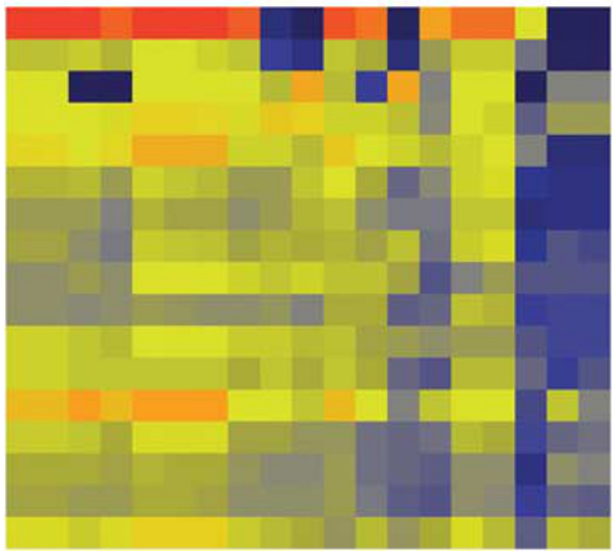

Figure 2 Reconstruction of KEGG pathways recovered from phylogenetic bins generated from the leaf-cutter ant fungus-garden metagenomes. KEGG profiles normalized by the number of predicted proteins in each phylogenetic bin were used for the clustering analysis. Pathways involved in the metabolism of carbohydrates, amino acids and B-vitamins were among the most highly represented and are shown here. 


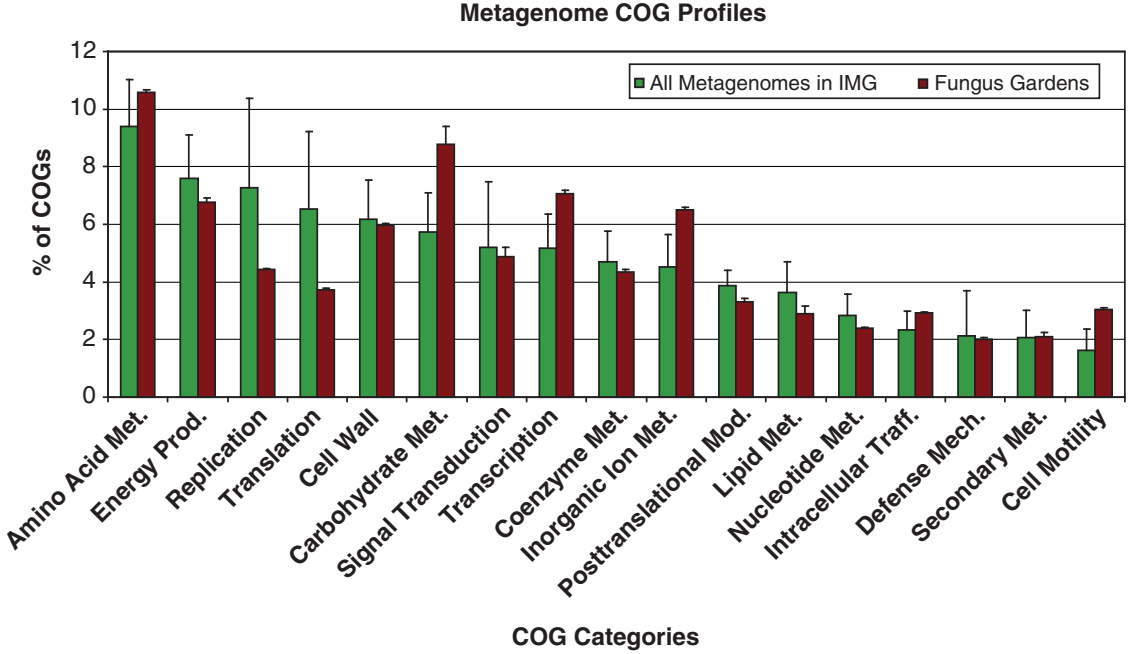

Figure 3 Comparison of the COG category distributions of the three combined fungus-garden metagenomes (A. colombica top, A. colombica bottom, and $A$. cephalotes combined) and all other metagenomes available in IMG. The average COG values are shown \pm s.d.

Table 4 Partial list of CAZymes identified in the leaf-cutter ant fungus-garden metagenomes, as compared with those found in the termite hindgut and wallaby foregut

\begin{tabular}{|c|c|c|c|c|c|c|}
\hline & $\begin{array}{c}\text { A. colombica } \\
\text { top }\end{array}$ & $\begin{array}{l}\text { A. colombica } \\
\text { bottom }\end{array}$ & A. cephalotes & Wallaby & Termite & Known activity \\
\hline \multicolumn{7}{|c|}{ Cellulases } \\
\hline GH5 & 5 & 2 & 2 & 20 & 97 & Cellulase, mannnosidase \\
\hline GH6 & 0 & 0 & 2 & 0 & 0 & Endocellulase, cellobiohydrolase \\
\hline GH9 & 0 & 2 & 0 & 4 & 39 & Endocellulase, cellobiohydrolase \\
\hline GH44 & 0 & 0 & 0 & 0 & 4 & Endoglucanase, xyloglucanase \\
\hline GH45 & 0 & 0 & 0 & 0 & 6 & Endoglucanase \\
\hline Total & $5(0.26 \%)$ & $4(0.24 \%)$ & $4(0.63 \%)$ & $24(2.3 \%)$ & $146(10.1 \%)$ & \\
\hline \multicolumn{7}{|c|}{ Hemicellulases } \\
\hline GH8 & 36 & 30 & 13 & 2 & 17 & Cellulase, xylanase, chitosanase \\
\hline GH10 & 0 & 1 & 3 & 18 & 92 & Xylanase \\
\hline GH11 & 0 & 0 & 0 & 0 & 18 & Xylanase \\
\hline GH28 & 13 & 11 & 3 & 10 & 13 & Polygalacturonase \\
\hline GH26 & 1 & 0 & 0 & 8 & 19 & Xylanase, mannanase \\
\hline GH53 & 1 & 4 & 0 & 3 & 5 & Endogalactanase \\
\hline Total & $51(2.6 \%)$ & $46(2.8 \%)$ & $19(2.9 \%)$ & $41(3.9 \%)$ & $164(11.3 \%)$ & \\
\hline \multicolumn{7}{|c|}{ Debranching enzymes } \\
\hline GH51 & 4 & 2 & 0 & 18 & 26 & Arabinofuranosidase \\
\hline GH67 & 2 & 0 & 0 & 0 & 6 & Glucuronidase \\
\hline GH78 & 25 & 14 & 4 & 52 & 7 & Rhamnosidases \\
\hline Total & $31(1.6 \%)$ & $16(0.98 \%)$ & $6(0.63 \%)$ & $70(6.8 \%)$ & $39(2.7 \%)$ & \\
\hline \multicolumn{7}{|c|}{ Oligosaccharide degrading enzymes } \\
\hline GH1 & $256^{\circ}$ & 243 & 77 & 84 & 27 & Glucosidase, galactosidase, mannosidase \\
\hline GH2 & 23 & 22 & 8 & 33 & 30 & Galactosidase, mannosidase, glucuronidase \\
\hline GH3 & 95 & 76 & 29 & 98 & 108 & Glucosidase, xylosidase \\
\hline GH4 & 61 & 55 & 35 & 3 & 17 & Galactosidase, glucosidase \\
\hline GH29 & 20 & 4 & 0 & 5 & 12 & Fucosidase \\
\hline GH35 & 11 & 1 & 0 & 10 & 6 & Galactosidase, glucosaminidase, \\
\hline GH36 & 26 & 24 & 9 & 29 & 4 & Galactosidase, N-acetylgalactosaminidase \\
\hline GH38 & 21 & 11 & 4 & 3 & 26 & Mannosidase \\
\hline GH39 & 1 & 0 & 0 & 3 & 11 & Xylosidase, iduronidase \\
\hline GH42 & 13 & 14 & 3 & 17 & 34 & Galactosidase \\
\hline GH43 & 39 & 36 & 11 & 3 & 57 & Arabinase, xylosidase \\
\hline GH52 & 0 & 0 & 0 & 0 & 3 & Xylosidase \\
\hline Total & $566(28.9 \%)$ & $486(29.6 \%)$ & $176(27.6 \%)$ & $288(27.9 \%)$ & $335(23.1 \%)$ & \\
\hline
\end{tabular}

The raw number of enzymes is given, as well as the percent of all CAZymes identified in individual metagenomes.

process (Table 4). The largest proportion of the identified proteins were most similar to oligosaccharidedegrading enzymes (176-566 CAZymes, 28-30\%), and relatively few were found to be predicted cellulases (4-5 CAZymes, 0.2-0.6\%). Compared with other well-known lignocellulose-degrading 
communities such as the Tammar wallaby foregut (Pope et al., 2010) and termite hindgut (Warnecke et al., 2007), fungus gardens contained relatively fewer cellulases and hemicellulases, but similar numbers of oligosaccharide-degrading enzymes.

\section{Comparison of Enterobacter populations}

To identify the similarities between the Enterobacter populations across different metagenomes, we performed a fragment recruitment analysis comparing all predicted genes from the Enterobacter FGI 35 phylogenetic bins from each metagenome with the draft Enterobacter FGI 35 genome (Figure 4). The fragment-recruitment analysis identified near-uniform coverage of $>95 \%$ nucleic acid identity BLAST hits across the 33 Enterobacter FGI 35 contigs, with the exception of four regions between 18-66 kb large that we termed variable regions I-IV. Moreover, we found that there was also nearuniform coverage of $70-85 \%$ identity BLASTN hits across the draft genome. Investigation of the coding potential in these conserved regions identified genes required for the synthesis of thiamine, pyridoxine, nicotinate, nicotinamide, pantothenate, folate and 19 amino acids. Only the later stages of the histidine biosynthetic pathway could be identified, although the full pathway is present in other Enterobacter contigs. These regions also encoded ABC transporters and phosphotransferase system components predicted to uptake cellobiose, xylose, glucose, sucrose, $\beta$-glucosides, arbutin or salicin, $N$-acetylmuramic acid, mannitol, mannose, sorbitol, galactitol, L-ascorbate, fructose, ribose, L-arabinose, methylgalactoside, sulfate, sulfonate, spermidine/putrescine, 2-aminoethylphosphonate, iron and other nutrients. The variable regions were found to contain primarily hypothetical genes and genes of unknown function, although some phage integrases were also identified.

\section{Metaproteomics}

Individual searches of the metaproteomic data against the predicted protein databases of each community metagenome recovered a total of 1186 redundant and 869 non-redundant peptides. Of all the distinct peptides recovered, 129 were found in both laboratory and field samples, while 351 were unique to the laboratory sample and 389 were unique to the field sample. A total of 747, 238 and 201 peptides were recovered for the searches against the A. cephalotes, A. colombica top and A. colombica bottom datasets, respectively. These peptides were mapped onto a total of 653 proteins, of which 354 were predicted from contigs or singletons that were phylogenetically binned as bacterial (see Supplementary Information for details on the phylogenetic binning procedure). The majority of bacterial proteins identified were predicted to belong to the Enterobacteriaceae, and functions predicted from these proteins included a variety of metabolic processes (Table 5, Supplementary Dataset 5). Figure 5 highlights the overlap observed between laboratory-reared samples and fieldcollected samples for one peptide mapped to a predicted glycosyl hydrolase. Details for all mass spectra and the annotations for the bacterial proteins they mapped to can be found in Supplementary Datasets 3 and 5 , respectively.

\section{Discussion}

Leaf-cutter ants are dominant New World herbivores, foraging on up to $17 \%$ of the foliar biomass in some ecosystems (Costa et al., 2009). In 1874 Thomas Belt established that leaf-cutters do not consume leaf material directly, as had been previously assumed, but instead use it as manure to cultivate a fungus for food in specialized gardens (Belt, 1874). For over a hundred years after Belt's

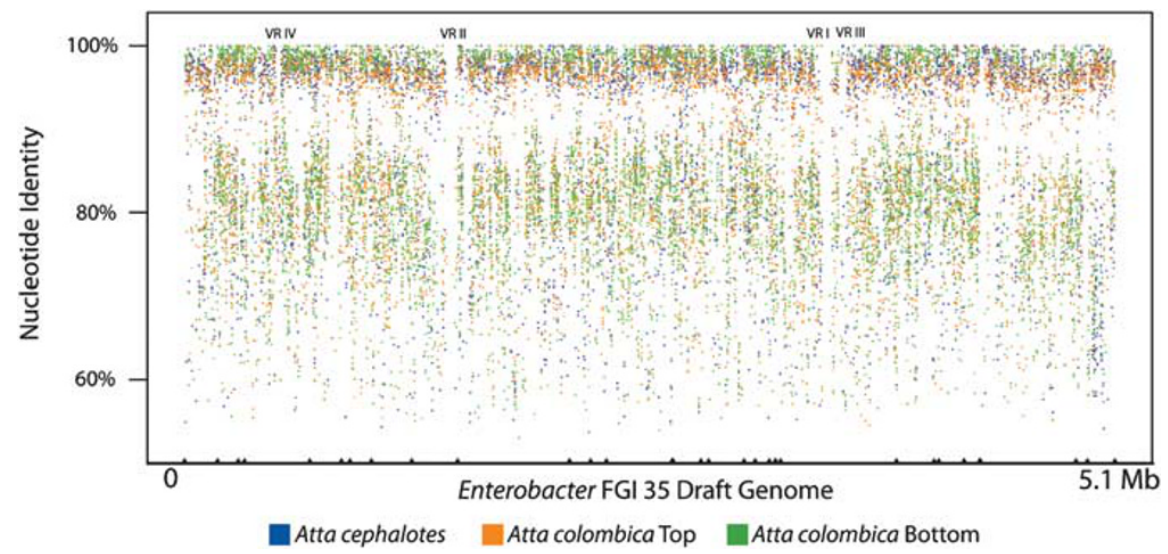

Figure 4 Fragment recruitment analysis of genes phylogenetically binned to Enterobacter FGI 35 against the draft Enterobacter FGI 35 genome. Each point indicates the best BLASTN match of a gene. Tick marks on the bottom indicate contig boundaries of the FGI 35 draft genome. Regions showing little or no coverage in the recruitment are marked on the top. 
Table 5 A subset of bacterial proteins identified in leaf-cutter ant fungus gardens using liquid chromatography-tandem mass spectrometry

\begin{tabular}{|c|c|c|c|c|c|c|}
\hline Function & $I M G / M I D$ & $\begin{array}{l}\text { Unique } \\
\text { peptides }\end{array}$ & $\begin{array}{l}\text { Coverage } \\
(\%)\end{array}$ & Metagenome & $\begin{array}{l}\text { Phylogenetic } \\
\text { bin }\end{array}$ & $\begin{array}{l}\text { KEGG pathway } \\
\text { annotation }\end{array}$ \\
\hline $\begin{array}{l}\text { Maltooligosaccharide ABC } \\
\text { transporter }\end{array}$ & 2030379576 & 1 & 11.5 & Atta cephalotes & Enterobacter & ABC transporters \\
\hline $\begin{array}{l}\text { ABC-type Fe3+-siderophore } \\
\text { transporter }\end{array}$ & 2030400032 & 1 & 15.0 & Atta cephalotes & Cronobacter & ABC transporters \\
\hline Molybdenum ABC transporter & 2030421739 & 1 & 23.6 & Atta cephalotes & Enterobacter & ABC transporters \\
\hline $\begin{array}{l}\text { ABC-type metal ion transport } \\
\text { system }\end{array}$ & 2030424448 & 1 & 17.5 & Atta colombica top & Cronobacter & ABC transporters \\
\hline ABC-type sugar transport systems & 2030547071 & 1 & 5.6 & Atta colombica top & Enterobacter & ABC transporters \\
\hline Nickel ABC transporter & 2030618419 & 1 & 13.7 & Atta cephalotes & Enterobacter & ABC transporters \\
\hline Nickel ABC transporter & 2030715302 & 1 & 13.7 & Atta colombica bottom & Enterobacter & ABC transporters \\
\hline Xylose-binding protein & 2030740215 & 1 & 20.3 & Atta colombica bottom & Enterobacter & ABC transporters \\
\hline $\begin{array}{l}\text { Sulfate ABC transporter, } \\
\text { permease protein }\end{array}$ & 2030755690 & 1 & 11.3 & Atta colombica bottom & Escherichia & ABC transporters \\
\hline $\begin{array}{l}\text { ABC-type Fe2+-enterobactin } \\
\text { transport system }\end{array}$ & 2030873639 & 1 & 19.7 & Atta colombica bottom & Citrobacter & ABC transporters \\
\hline Glutamate 5-kinase & 2030382776 & 1 & 30.6 & Atta cephalotes & Citrobacter & $\begin{array}{l}\text { Arginine and proline } \\
\text { metabolism }\end{array}$ \\
\hline $\begin{array}{l}\text { Arginine/lysine/ornithine } \\
\text { decarboxylases }\end{array}$ & 2030746280 & 1 & 18.3 & Atta colombica bottom & Shigella & $\begin{array}{l}\text { Arginine and proline } \\
\text { metabolism }\end{array}$ \\
\hline Argininosuccinate lyase & 2030440723 & 1 & 26.8 & Atta colombica top & Escherichia & $\begin{array}{l}\text { Arginine and proline } \\
\text { metabolism; alanine, aspartate } \\
\text { and glutamate metabolism }\end{array}$ \\
\hline $\begin{array}{l}\text { Dihydrolipoamide } \\
\text { dehydrogenase }\end{array}$ & 2030822927 & 1 & 17.7 & Atta colombica bottom & Escherichia & $\begin{array}{l}\text { Glycine, serine and threonine } \\
\text { metabolism; } \\
\text { pyruvate metabolism }\end{array}$ \\
\hline $\begin{array}{l}\text { Dihydrolipoamide } \\
\text { dehydrogenase }\end{array}$ & 2030836212 & 1 & 16.2 & Atta colombica bottom & Pantoea & $\begin{array}{l}\text { Glycine, serine and threonine } \\
\text { metabolism; } \\
\text { pyruvate metabolism }\end{array}$ \\
\hline Phosphoserine phosphatase & 2030692072 & 1 & 9.9 & Atta colombica bottom & Cronobacter & $\begin{array}{l}\text { Glycine, serine and threonine } \\
\text { metabolism }\end{array}$ \\
\hline Serine hydroxymethyltransferase & 2030486384 & 2 & 26.8 & Atta colombica top & Erwinia & $\begin{array}{l}\text { Glycine, serine and threonine } \\
\text { metabolism }\end{array}$ \\
\hline Serine hydroxymethyltransferase & 2030517753 & 1 & 12.6 & Atta colombica top & Citrobacter & $\begin{array}{l}\text { Glycine, serine and threonine } \\
\text { metabolism }\end{array}$ \\
\hline Serine hydroxymethyltransferase & 2030694137 & 1 & 14.4 & Atta colombica bottom & Pantoea & $\begin{array}{l}\text { Glycine, serine and threonine } \\
\text { metabolism }\end{array}$ \\
\hline Phosphoglycerate dehydrogenase & 2030414422 & 1 & 5.3 & Atta cephalotes & Pantoea & $\begin{array}{l}\text { Glycine, serine and threonine } \\
\text { metabolism; glyoxylate } \\
\text { metabolism }\end{array}$ \\
\hline Phosphoglycerate dehydrogenase & 2030784320 & 1 & 11.0 & Atta colombica bottom & Pantoea & $\begin{array}{l}\text { Glycine, serine and threonine } \\
\text { metabolism; glyoxylate } \\
\text { metabolism }\end{array}$ \\
\hline $\begin{array}{l}N \text {-formylglutamate } \\
\text { amidohydrolase }\end{array}$ & 2030458338 & 1 & 21.5 & Atta colombica top & Pseudomonas & Histidine metabolism \\
\hline $\begin{array}{l}\text { UDP- } N \text {-acetylmuramyl } \\
\text { pentapeptide synthase }\end{array}$ & 2030358109 & 1 & 9.9 & Atta cephalotes & Cronobacter & $\begin{array}{l}\text { Lysine biosynthesis; } \\
\text { peptidoglycan biosynthesis. }\end{array}$ \\
\hline $\begin{array}{l}\text { Assimilatory nitrate reductase } \\
\text { (NADH) beta subunit }\end{array}$ & 2030622199 & 1 & 16.7 & Atta colombica top & Enterobacter & Nitrogen metabolism \\
\hline Ketopantoate reductase & 2030492465 & 1 & 11.5 & Atta colombica top & Salmonella & $\begin{array}{l}\text { Pantothenate and CoA } \\
\text { biosynthesis }\end{array}$ \\
\hline Dephospho-CoA kinase & 2030638227 & 1 & 8.3 & Atta colombica top & Cronobacter & $\begin{array}{l}\text { Pantothenate and CoA } \\
\text { biosynthesis }\end{array}$ \\
\hline Dephospho-CoA kinase & 2030765884 & 1 & 8.3 & Atta colombica bottom & Cronobacter & $\begin{array}{l}\text { Pantothenate and CoA } \\
\text { biosynthesis }\end{array}$ \\
\hline Ketol-acid reductoisomerase & 2030484311 & 1 & 14.7 & Atta colombica top & Cronobacter & $\begin{array}{l}\text { Pantothenate and CoA } \\
\text { biosynthesis; valine, } \\
\text { leucine and isoleucine } \\
\text { biosynthesis }\end{array}$ \\
\hline Ketol-acid reductoisomerase & 2030706777 & 1 & 14.4 & Atta colombica bottom & Enterobacter & $\begin{array}{l}\text { Pantothenate and CoA } \\
\text { biosynthesis; valine, } \\
\text { leucine and isoleucine } \\
\text { biosynthesis }\end{array}$ \\
\hline $\begin{array}{l}\text { 2,3-Dihydroxyphenylpropionate } \\
\text { 1,2-dioxygenase }\end{array}$ & 2030383282 & 1 & 16.3 & Atta cephalotes & Escherichia & Phenylalanine metabolism \\
\hline $\begin{array}{l}\text { Phenylacetaldehyde } \\
\text { dehydrogenase }\end{array}$ & 2030382676 & 1 & 6.0 & Atta cephalotes & Enterobacter & Phenylalanine metabolism \\
\hline $\begin{array}{l}\text { Phosphoribosylanthranilate } \\
\text { isomerase }\end{array}$ & 2030473537 & 1 & 23.5 & Atta colombica top & Pseudomonas & $\begin{array}{l}\text { Phenylalanine, tyrosine and } \\
\text { tryptophan biosynthesis }\end{array}$ \\
\hline PTS system IIB component & 2030657658 & 1 & 11.0 & Atta colombica top & Enterobacter & Phosphotransferase system \\
\hline PTS system IIB component & 2030453403 & 1 & 11.5 & Atta colombica bottom & Enterobacter & Phosphotransferase system \\
\hline PTS system & 2030849317 & 1 & 8.4 & Atta cephalotes & Klebsiella & Phosphotransferase system \\
\hline
\end{tabular}


Table 5 (Continued)

\begin{tabular}{|c|c|c|c|c|c|c|}
\hline Function & $I M G / M I D$ & $\begin{array}{l}\text { Unique } \\
\text { peptides }\end{array}$ & $\begin{array}{l}\text { Coverage } \\
(\%)\end{array}$ & Metagenome & $\begin{array}{l}\text { Phylogenetic } \\
\text { bin }\end{array}$ & $\begin{array}{l}\text { KEGG pathway } \\
\text { annotation }\end{array}$ \\
\hline Coproporphyrinogen III oxidase & 2030365066 & 1 & 5.3 & Atta cephalotes & Klebsiella & $\begin{array}{l}\text { Porphyrin and } \\
\text { chlorophyll metabolism }\end{array}$ \\
\hline $\begin{array}{l}\text { Alpha-1,4-glucan } \\
\text { 6-glycosyltransferase }\end{array}$ & 2030357778 & 1 & 4.7 & Atta cephalotes & Enterobacter & Starch and sucrose metabolism \\
\hline Glycosyl hydrolase family 3 & 2030378568 & 1 & 11.5 & Atta colombica top & Herbaspirillum & Starch and sucrose metabolism \\
\hline Glycosyl hydrolase family 4 & 2030380706 & 1 & 8.1 & Atta cephalotes & Enterobacter & Starch and sucrose metabolism \\
\hline Sulfite reductase (NADPH) & 2030777085 & 1 & 7.3 & Atta colombica bottom & Cronobacter & Sulfur metabolism \\
\hline Cysteine synthase & 2030364558 & 2 & 14.2 & Atta cephalotes & Enterobacter & $\begin{array}{l}\text { Sulfur metabolism; cysteine and } \\
\text { methionine metabolism }\end{array}$ \\
\hline Cysteine synthase & 2030392152 & 1 & 10.2 & Atta cephalotes & Cronobacter & $\begin{array}{l}\text { Sulfur metabolism; cysteine and } \\
\text { methionine metabolism }\end{array}$ \\
\hline Cysteine synthase & 2030462672 & 1 & 12.4 & Atta colombica top & Enterobacter & $\begin{array}{l}\text { Sulfur metabolism; Cysteine and } \\
\text { methionine metabolism }\end{array}$ \\
\hline
\end{tabular}

Proteins of interest are listed with their annotation, unique IMG/M identifiers, number of peptides matching, \% coverage in the proteome, metagenome of origin, phyogenetic bin, and predicted KEGG pathway. The peptides used to construct this table were manually annotated, and details are available in Supplementary Dataset S6. All bacterial proteins characterized in the metaproteome can be seen in Supplementary Dataset S5, and details of all peptides identified can be found in Supplementary Dataset S3.

a

\begin{tabular}{|c|c|c|c|c|c|c|c|c|c|c|c|c|c|c|c|}
\hline$\#$ & 1 & 2 & 3 & 4 & 5 & 6 & 7 & 8 & 9 & 10 & 11 & 12 & 13 & 14 & 15 \\
\hline b ions & & 185.13 & 256.17 & 371.19 & 484.28 & 597.36 & 744.43 & 801.45 & 916.48 & 1015.55 & 1129.59 & 1226.64 & 1313.67 & 1370.70 & \\
\hline Peptide & A & 1 & A & D & L & L & $F$ & G & D & V & $\mathrm{N}$ & P & S & G & K \\
\hline$y$ ions & 1516.80 & 1445.76 & 1332.68 & 1261.64 & 1146.61 & 1033.53 & 920.45 & 773.38 & 716.36 & 601.33 & 502.26 & 388.22 & 291.17 & 204.13 & 147.11 \\
\hline$\#$ & 15 & 14 & 13 & 12 & 11 & 10 & 9 & 8 & 7 & 6 & 5 & 4 & 3 & 2 & 1 \\
\hline
\end{tabular}

b

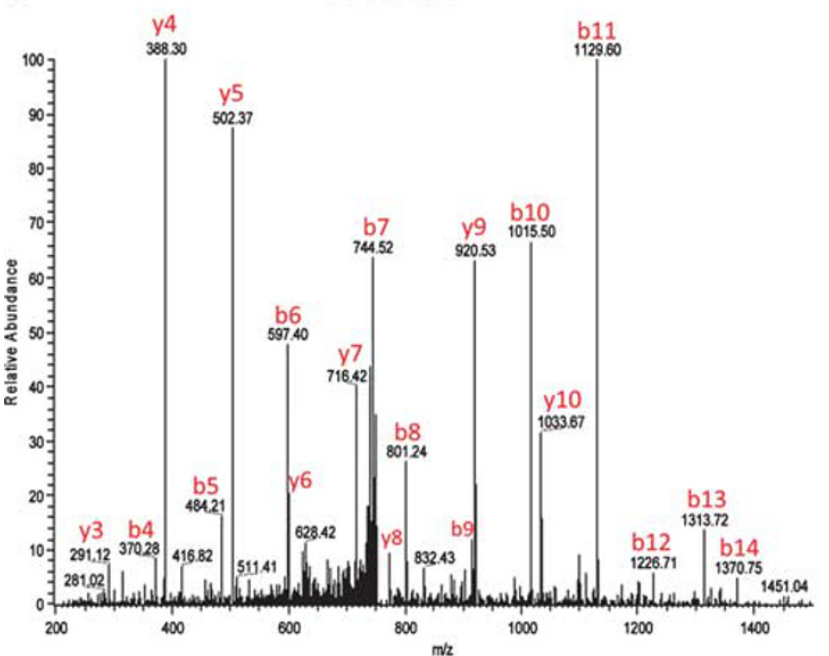

c

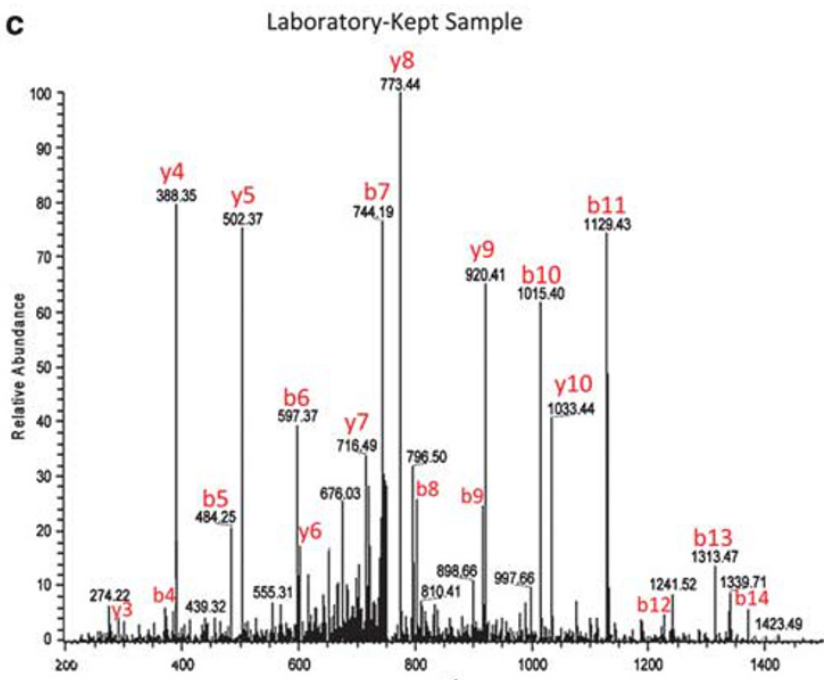

Figure 5 Example of overlap between field-collected and laboratory-reared fungus-garden samples for the glycoside hydrolase family 3 peptide N.AIADLLFGDVNPSGK.L. (a) Theoretical $b$ and $y$ ions, identified $m / z$ values are highlighted in red. (b) Field sample MS/MS spectra; instrument, LTQ Orbitrap (high mass accuracy MS, low mass accuracy MS/MS); parent ion p.p.m. error, 4.03; peptide charge state, +2; retention time, $42.72 \mathrm{~min}$; XCorr, 4.19; MS-GF spectra probability, $1.42 \times 10^{-13}$. (c) Laboratory-kept sample MS/MS spectra; instrument, LTQ Orbitrap (high mass accuracy MS, low mass accuracy MS/MS); parent ion p.p.m. error, 3.06; peptide charge state, + 2; retention time, $33.36 \mathrm{~min}$; XCorr, 4.08; MS-GF spectra probability, $1.67 \times 10^{-12}$. Manual annotation of additional peptides of interest can be found in Supplementary Dataset 6.

pioneering discovery it was believed that the fungus gardens of leaf-cutter ants represented a monoculture of the fungal cultivar that degraded plant cellwall material and converted it into nutrients for the ants (Weber, 1966; Martin and Weber, 1969). However, both the lignocellulolytic capacity of the cultivar and the view that fungus gardens are composed solely of the fungal mutualist have been recently challenged (Gomes De Siqueira et al., 1998; Abril and Bucher, 2002; Scott et al., 2010; Suen et al., 2010). In this study, we explored the hypothesis that bacteria are common constituents of fungus gardens that could be participating in plant biomass degradation and nutrient cycling.

Our work demonstrates that a distinct community of bacteria resides in the fungus gardens of A. colombica and A. cephalotes leaf-cutter ants. Our identification of similar bacterial groups in fungus-garden samples taken from different ant species and garden strata supports this conclusion. 
Moreover, this is consistent with our finding that relatively few bacterial genera comprise the majority of the metagenomic sequences recovered in this study (see below). This, combined with the previous work on nitrogen fixation, plant biomass degradation and membrane-lipid profiles in these ecosystems, indicates that bacteria are long-term residents of fungus gardens and not merely allochthonous organisms introduced from leaf material or the surrounding soil (Bacci et al., 1995; Pinto-Tomas et al., 2009; Scott et al., 2010; Suen et al., 2010). Thus, the term 'fungus garden' may be misleading, as these environments are composed of a fungusbacteria community.

The bacterial component of the microbial ecosystem in fungus gardens appears to be dominated by only a few groups. Specifically, the genera Enterobacter, Klebsiella, Citrobacter, Escherichia and Pantoea represent over two-thirds of the bacterial component in each of the community metagenomes (Figure 1d). This narrow genus-level diversity is likely the result of both the nutrient composition of the plant-fungal matrix and the meticulous hygienic practices of the ants. For example, leaf-cutters continuously weed their gardens to remove areas infected with microbial pathogens (Currie and Stuart, 2001), and also apply antimicrobials derived from both glandular secretions and symbiotic actinobacteria (Currie et al., 1999; Fernández-Marín et al., 2006). The extent of plant biomass degradation could also affect microbial diversity, but if this was a critical factor we would expect to find distinct communities between top and bottom garden strata, which contain fresh leaf material and largely degraded biomass, respectively. The similarity between different strata observed here, consistent with previous work reporting little difference between 16S libraries constructed from these two regions (Suen et al., 2010), indicates that the extent of plant biomass degradation is not a major contributor to community structuring. The consistent presence of bacterial groups within the Enterobacteriaceae throughout different garden strata and leaf-cutter ant species implicates them as having a consistent role in fungus gardens, and suggests that these environments represent highly structured communities rather than a random collection of opportunistic microbes. Although it remains a possibility that while removing the fungal matrix and plant debris from fungus gardens our analysis excluded microbial groups adhering to fungal or plant biomass, thereby skewing the composition of the metagenomes, our results are generally consistent with previous culture-independent investigations that either analyzed whole fungus gardens or utilized different methods to isolate bacterial cells (Scott et al., 2010; Suen et al., 2010). Moreover, our processing of fresh rather than frozen fungusgarden material may be partially responsible for our success in removing fungal or plant debris from our samples.
Bacteria of the genus Enterobacter appear to be particularly prevalent in fungus gardens. In contrast to the narrow genus-level diversity observed in these environments, multiple species of Enterobacter appear to be present in all the gardens analyzed. Our fragment-recruitment analysis demonstrates that populations of bacteria with $>95 \%$ and $70-85 \%$ nucleic acid identity to the reference Enterobacter FGI 35 genome exist in these environments (Figure 4). The four large gaps identified in the recruitment plot likely represent prophage or other variable elements in the reference genome. Because Enterobacter FGI 35 was isolated from an $A$. colombica fungus garden, the nearuniform coverage of genes at $>95 \%$ identity across all metagenomes indicates that highly similar strains of Enterobacter are present in all of the samples analyzed. The near-uniform coverage of genes at $70-85 \%$ identity likely represents multiple distinct species, as it is improbable that genes from a single population of bacteria would have such a large range of nucleotide identity to a single reference genome. Genes $70-85 \%$ identical to the Enterobacter FGI 35 genome may represent divergent Enterobacter species or even novel Enterobacteriaceae for which an appropriate reference for phylogenetic binning does not exist. That different species of leaf-cutter ant harbor abundant Enterobacter populations indicates that this group may be an important constituent of the fungusgarden community.

The overall functional potential of the metagenomes includes a diversity of bacterial genes associated with plant biomass degradation, supporting previous work that has suggested a role for bacteria in this process. The vast majority of CAZymes identified in the metagenomes are associated with oligosaccharide degradation or simple sugar metabolism, suggesting that bacteria are processing partially degraded plant material. We also found KEGG pathways involved in hexose and pentose sugar metabolism to be highly represented in the Enterobacteriaceae, indicating that sugar monomers can be readily metabolized by many of these bacteria. Moreover, our KEGG, COG and metaproteomic analyses recovered numerous sugar transporters (Figure 2, Table 5, Supplementary Dataset 2), including a large number of cellobiose-specific phosphotransferase system components that are known to be involved in the uptake of the byproducts of cellulose hydrolysis (Figure 1, Table 5, Supplementary Dataset 2). Together, these data suggest that bacterial community members are metabolizing predominantly partially degraded plant material, although it remains a possibility that unidentified bacterial lignocellulases also have a role in the degradation of more recalcitrant biomass.

Bacterial lineages in fungus gardens were also found to possess diverse biosynthetic pathways. Pathways involved in amino-acid and B-vitamin metabolism were particularly well-represented in 
the detected Enterobacteriaceae and Pseudomonas sequences, and biosynthetic pathways for thiamin, pyridoxine, nicotinate, nicotinamide, pantothenate, folate, and all 20 amino acids could be reconstructed from the Enterobacter bins. As mentioned above, enzymes involved in the metabolism of oligosaccharides and simple sugars were also identified in many of these groups, indicating that they may convert carbon-rich plant biomass into amino acids, B-vitamins, proteins or other nutrients. Previous work has indicated that bacteria have a role in the introduction and cycling of nitrogen in fungus gardens (Pinto-Tomas et al., 2009). Together with our work, this suggests that the combined metabolism of resident bacteria may enrich the nutrient composition of fungus gardens through the conversion of carbohydrate-rich oligosaccharides into a variety of other nutrients that could promote the growth of the fungal cultivar or even nourish the ants themselves.

Our metaproteomic analysis recovered peptides mapping to bacterial proteins predicted to participate in biomass degradation and nutrient biosynthesis, supporting the results of our metagenomic characterization and further indicating that bacteria are involved in these processes (Table 5, Supplementary Datasets 3, 5, and 6). Our manual inspection of the metaproteomic data identified multiple peptides belonging to glycoside hydrolases, sugar transporters and amino acid and B-vitamin biosynthetic pathways. That multiple peptides could be assigned to proteins with similar predicted functions indicates that these processes may be prevalent in fungus gardens. Moreover, many of the mapped peptides originated from both laboratoryreared and field-collected samples, including one that belonged to a family 3 glycosyl hydrolase (Figure 5). Although these data should be interpreted cautiously due to the few bacterial proteins identified overall, this may indicate physiological similarities between bacteria in laboratory-reared versus field-collected colonies.

Not all bacteria in fungus gardens were found to have substantial biosynthetic capacity, and in particular the Lactococcus groups appeared to have limited coding potential in the majority of pathways analyzed. This may be a result of lower sequencing coverage, as only a relatively small fraction of the metagenomes was predicted to belong to these groups. Alternatively, these groups may not be contributing substantially to nutrient cycling and are able to subsist on free sugars and other nutrients available in fungus gardens. Importantly, the byproducts of Lactococci metabolism may acidify fungus gardens and contribute to the maintenance of the lower $\mathrm{pH}$ in these ecosystems, which has previously been observed at 4.4-5.0 (Powell and Stradling, 1986). Regulation of the $\mathrm{pH}$ of fungus gardens to this narrow range has been hypothesized to be critical to the growth of fungal cultivar, but the mechanism through which this occurs has remained unknown (Powell and Stradling, 1986). Few peptides from our metaproteomic data sets were recovered from this group, indicating that they may be present in low abundance.

In addition to bacteria, we also found that fungus gardens contain substantial populations of bacteriophage (Figure 1). These organisms could play key roles by limiting bacterial abundance or decreasing ecosystem productivity. Moreover, because fungus gardens contain numerous closely related genera in the Enterobacteriaceae, bacteriophage could provide a common mechanism for gene transfer between lineages. The presence of bacteriophage in fungus gardens adds to the number of organisms that are shaping these ecosystems and introduces a new layer of complexity into the ecology of fungus gardens.

Metagenomics and metaproteomics have previously been shown to be invaluable tools for analyzing microbial communities (Ram et al., 2005; Gill et al., 2006; Woyke et al., 2006; Kalyuzhnaya et al., 2008; Wilmes et al., 2008; Allgaier et al., 2009; Verberkmoes et al., 2009; Burnum et al., 2011), including those associated with herbivores (Warnecke et al., 2007; Brulc et al., 2009; Pope et al., 2010; Burnum et al., 2011). Here we use these techniques to provide insight into the fungus gardens of leaf-cutter ants. Our work shows that relatively few genera dominate the bacterial fraction of these communities, and that the genus Enterobacter appears to be particularly prevalent. We show that bacteria have diverse metabolic potential associated with the degradation of plant biomass, and we confirm the production of two bacterial glycoside hydrolases in situ. Moreover, we show that bacteria in fungus gardens likely participate in the biosynthesis of amino acids, B-vitamins and other nutrients that potentially enhance the growth or biomass-processing efficiency of the fungal cultivar. This is consistent with a model of synergistic biomass degradation by a fungus-bacteria consortium. Our work enhances our knowledge of how leaf-cutter ants process massive quantities of plant biomass in their ancillary digestive systems, and underscores the importance of symbiotic communities on the evolution and ecology of herbivores.

\section{Acknowledgements}

We thank the staff of the Joint Genome Institute, Pacific Northwest National Laboratories, and the Smithsonian Tropical Research Institute for their expertise and support in the collection and processing of all samples, in particular S Malfatti, L Seid, Y Clemons, R Urriola, M Paz and O Arosemena. We thank all members of the Currie lab for their comments on the manuscript. We also thank three anonymous reviewers for their comments on the manuscript. The US Department of Energy Joint Genome Institute effort was supported by the Office of Science of the US Department of Energy under Contract No. DE-AC02-05CH11231. Proteomic work was performed in 
the Environmental Molecular Sciences Laboratory, a US Department of Energy (DOE) Office of Biological and Environmental Research national scientific user facility on the Pacific Northwest National Laboratory (PNNL) campus. Portions of this research were supported by the US Department of Energy's (DOE) Office of Biological and Environmental Research (OBER) Panomics program. PNNL is a multiprogram national laboratory operated by Battelle for the DOE under Contract DE-AC05-76RL01830. This work is also supported by the National Science Foundation (grants DEB-0747002, MCB-0702025, and MCB-0731822 to CRC) and the DOE Great Lakes Bioenergy Research Center (DOE Office of Science BER DE-FC0207ER64494).

\section{References}

Abril AB, Bucher EH. (2002). Evidence that the fungus cultured by leaf-cutting ants does not metabolize cellulose. Ecol Lett 5: 325-328.

Allgaier M, Reddy A, Park JI, Ivanova N, D’Haeseleer P, Lowry S et al. (2009). Targeted discovery of glycoside hydrolases from a switchgrass-adapted compost community. PLoS One 5: e8812.

Angly FE, Willner D, Prieto-Davo A, Edwards RA, Schmieder R, Vega-Thurber R et al. (2009). The GAAS metagenomic tool and its estimations of viral and microbial average genome size in four major biomes. PLoS Comput Biol 5: e1000593.

Bacci M, Ribeiro SB, Casarotto MEF, Pagnocca FC. (1995). Biopolymer-degrading bacteria from nests of the leafcutting ant Atta Sexdens Rubropilosa. Braz J Med Biol Res 28: 79-82.

Belt T. (1874). The Naturalist in Nicaragua. E. Bumpus: London.

Brulc JM, Antonopoulos DA, Miller ME, Wilson MK, Yannarell AC, Dinsdale EA et al. (2009). Gene-centric metagenomics of the fiber-adherent bovine rumen microbiome reveals forage specific glycoside hydrolases. Proc Natl Acad Sci USA 106: 1948-1953.

Burnum KE, Callister SJ, Nicora CD, Purvine SO, Hugenholtz P, Warnecke F et al. (2011). Proteome insights into the symbiotic relationship between a captive colony of Nasutitermes corniger and its hindgut microbiome. ISME J 5: 161-164.

Cantarel BL, Coutinho PM, Rancurel C, Bernard T, Lombard V, Henrissat B. (2009). The CarbohydrateActive EnZymes database (CAZy): an expert resource for glycogenomics. Nucleic Acids Res 37(Database issue): D233-D238.

Chapela IH, Rehner SA, Schultz TR, Mueller UG. (1994). Evolutionary history of the symbiosis between fungus-growing ants and their fungi. Science 266: 1691-1694.

Costa AN, Vasconcelos HL, Vieira-Neto EHM, Bruna EM. (2009). Do herbivores exert top-down effects in Neotropical savannas? Estimates of biomass consumption by leaf-cutter ants. J Veg Sci 19: 849-854.

Currie CR, Scott JA, Summerbell RC, Malloch D. (1999). Fungus-growing ants use antibiotic-producing bacteria to control garden parasites. Nature 398: 701-704.

Currie CR, Stuart AE. (2001). Weeding and grooming of pathogens in agriculture by ants. Proc $R$ Soc Lond $B$ Biol Sci 268: 1033-1039.
De Fine Licht HH, Schiott M, Mueller UG, Boomsma JJ. (2010). Evolutionary transitions in enzyme activity of ant fungus gardens. Evolution 64: 2055-2069.

Eng J, McCormack A, Yates J. (1994). An approach to correlate tandem mass spectral data of peptides with amino acid sequences in a protein database. J Am Soc Mass Spectrom 5: 976-989.

Fernández-Marín H, Zimmerman JK, Rehner SA, Wcislo WT. (2006). Active use of the metaplural glands by ants in controlling fungal infection. Proc $R$ SoC London B Biol Sci 273: 1689-1695.

Gill SR, Pop M, Deboy RT, Eckburg PB, Turnbaugh PJ, Samuel BS et al. (2006). Metagenomic analysis of the human distal gut microbiome. Science 312: 1355-1359.

Gomes De Siqueira C, Bacci Jr M, Pagnocca FC, Bueno OC, Hebling MJA. (1998). Metabolism of plant polysaccharides by Leucoagaricus gongylophorus, the symbiotic fungus of the leaf-cutting ant Atta sexdens. Appl Environ Microbiol 64: 4820-4822.

Haeder S, Wirth R, Herz H, Spiteller D. (2009). Candicidinproducing Streptomyces support leaf-cutting ants to protect their fungus garden against the pathogenic fungus Escovopsis. Proc Natl Acad Sci USA 106: 4742-4746.

Hölldobler B, Wilson EO. (1990). The Ants. Harvard University Press: Cambridge, MA.

Hölldobler B, Wilson EO. (2008). The Superorganism: The Beauty, Elegance, and Strangeness of Insect Societies. W. W. Norton \& Company: New York, NY.

Hölldobler B, Wilson EO. (2010). The Leafcutter Ants: Civilization by Instinct. W. W. Norton \& Company: New York, NY.

Kalyuzhnaya MG, Lapidus A, Ivanova N, Copeland AC, McHardy AC, Szeto E et al. (2008). High-resolution metagenomics targets specific functional types in complex microbial communities. Nat Biotechnol 26: 1029-1034.

Kanehisa M, Araki M, Goto S, Hattori M, Hirakawa M, Itoh $\mathrm{M}$ et al. (2008). KEGG for linking genomes to life and the environment. Nucleic Acids Res 36(Database issue): D480-D484.

Kim S, Gupta N, Pevzner PA. (2008). Spectral probabilities and generating functions of tandem mass spectra: a strike against decoy databases. J Proteome Res 7: 3354-3363.

Margulies M, Egholm M, Altman WE, Attiya S, Bader JS, Bemben LA et al. (2005). Genome sequencing in microfabricated high-density picolitre reactors. Nature 437: 376-380.

Markowitz VM, Ivanova NN, Szeto E, Palaniappan K, Chu K, Dalevi D et al. (2008). IMG/M: a data management and analysis system for metagenomes. Nucleic Acids Res 36(Database issue): D534-D538.

Martin MM, Weber NA. (1969). The cellulose-utilizing capability of the fungus cultured by the attine ant Atta colombica tonsipes. Ann Entomol Soc Am 62: 1386-1387.

Mueller U, Gerardo N, Aanen D, Six D, Schultz T. (2005). The evolution of agriculture in insects. Annu Rev Ecol Evol Syst 36: 563-595.

Pinto-Tomas AA, Anderson MA, Suen G, Stevenson DM, Chu FS, Cleland WW et al. (2009). Symbiotic nitrogen fixation in the fungus gardens of leaf-cutter ants. Science 326: 1120-1123.

Pope PB, Denman SE, Jones M, Tringe SG, Barry K, Malfatti SA et al. (2010). Adaptation to herbivory by the Tammar wallaby includes bacterial and glycoside 
hydrolase profiles different from other herbivores. Proc Natl Acad Sci USA 107: 14793-14798.

Powell RJ, Stradling DJ. (1986). Factors influencing the growth of Attamyces bromatificus, a symbiont of the attine ants. Trans Br Mycol Soc 87: 205-213.

Ram RJ, Verberkmoes NC, Thelen MP, Tyson GW, Baker BJ, Blake II RC et al. (2005). Community proteomics of a natural microbial biofilm. Science 308: 1915-1920.

Santos AV, Dillon RJ, Dillon VM, Reynolds SE, Samuels RI. (2004). Ocurrence of the antibiotic producing bacterium Burkholderia sp. in colonies of the leafcutting ant Atta sexdens rubropilosa. FEMS Microbiol Lett 239: 319-323.

Schiott M, De Fine Licht HH, Lange L, Boomsma JJ. (2008). Towards a molecular understanding of symbiont function: identification of a fungal gene for the degradation of xylan in the fungus gardens of leafcutting ants. BMC Microbiol 8: 40.

Schiott M, Rogowska-Wrzesinska A, Roepstorff P, Boomsma JJ. (2010). Leaf-cutting ant fungi produce cell wall degrading pectinase complexes reminiscent of phytopathogenic fungi. BMC Biol 8: 156.

Schultz TR, Brady SG. (2008). Major evolutionary transitions in ant agriculture. Proc Natl Acad Sci USA 105: 5435-5440.

Scott JJ, Budsberg KJ, Suen G, Wixon DL, Balser TC, Currie CR. (2010). Microbial community structure of leafcutter ant fungus gardens and refuse dumps. PLoS One 5: e9922.

Semenova TA, Hughes DP, Boomsma JJ, Schiott M. (2011). Evolutionary patterns of proteinase activity in attine ant fungus gardens. BMC Microbiol 11: 15.

Silva A, Bacci Jr M, Pagnocca FC, Bueno OC, Hebling MJ. (2006a). Production of polysaccharidases in different carbon sources by Leucoagaricus gongylophorus Moller (Singer), the symbiotic fungus of the leaf-cutting ant Atta sexdens Linnaeus. Curr Microbiol 53: $68-71$.

Silva A, Bacci Jr M, Pagnocca FC, Bueno OC, Hebling MJ. (2006b). Starch metabolism in Leucoagaricus gongylophorus, the symbiotic fungus of leaf-cutting ants. Microbiol Res 161: 299-303.

Suen G, Scott JJ, Aylward FO, Adams SM, Tringe SG, Pinto-Tomas AA et al. (2010). An insect herbivore microbiome with high plant biomass-degrading capacity. PLoS Genet 6: e1001129.

Tatusov RL, Natale DA, Garkavtsev IV, Tatusova TA, Shankavaram UT, Rao BS et al. (2001). The COG database: new developments in phylogenetic classification of proteins from complete genomes. Nucleic Acids Res 29: 22-28.

Verberkmoes NC, Russell AL, Shah M, Godzik A, Rosenquist M, Halfvarson J et al. (2009). Shotgun metaproteomics of the human distal gut microbiota. ISME J 3: 179-189.

Warnecke F, Luginbuhl P, Ivanova N, Ghassemian M, Richardson TH, Stege JT et al. (2007). Metagenomic and functional analysis of hindgut microbiota of a wood-feeding higher termite. Nature 450: 560-565.

Weber NA. (1966). Fungus-growing ants. Science 153: 587-604.

Wilmes P, Wexler M, Bond PL. (2008). Metaproteomics provides functional insight into activated sludge wastewater treatment. PLoS One 3: e1778.

Woyke T, Teeling H, Ivanova NN, Huntemann M, Richter M, Gloeckner FO et al. (2006). Symbiosis insights through metagenomic analysis of a microbial consortium. Nature 443: 950-955.

Supplementary Information accompanies the paper on The ISME Journal website (http://www.nature.com/ismej) 